\title{
Development and Clinical Application of a Panfungal PCR Assay To Detect and Identify Fungal DNA in Tissue Specimens ${ }^{\nabla}$
}

\author{
Anna Lau, ${ }^{1}$ Sharon Chen, ${ }^{2,3}$ Tania Sorrell, ${ }^{1,2}$ Dee Carter ${ }^{4}$ Richard Malik, ${ }^{5,6}$ \\ Patricia Martin, ${ }^{6}$ and Catriona Halliday ${ }^{2,3 *}$

\begin{abstract}
Faculty of Medicine, ${ }^{1}$ Centre for Infectious Diseases and Microbiology, Westmead Millennium Institute, ${ }^{2}$ School of Molecular and Microbial Biosciences, ${ }^{4}$ Post Graduate Foundation in Veterinary Science, ${ }^{5}$ and Veterinary Pathology Diagnostic Services, Faculty of Veterinary Science, ${ }^{6}$ University of Sydney, and Centre for Infectious Diseases and Microbiology Laboratory Services, Institute of Clinical Pathology and Medical Research, Sydney West Area Health Service, ${ }^{3}$ Sydney, New South Wales, Australia
\end{abstract}

Received 8 September 2006/Returned for modification 7 November 2006/Accepted 15 November 2006

\begin{abstract}
Given the rise in the incidence of invasive fungal infections (IFIs) and the expanding spectrum of fungal pathogens, early and accurate identification of the causative pathogen is essential. We developed a panfungal PCR assay that targets the internal transcribed spacer 1 (ITS1) region of the ribosomal DNA gene cluster to detect fungal DNA in fresh and formalin-fixed, paraffin-embedded (PE) tissue specimens from patients with culture-proven $(n=38)$ or solely histologically proven $(n=24)$ IFIs. PCR products were sequenced and compared with sequences in the GenBank database to identify the causal pathogen. The molecular identification was correlated with results from histological examination and culture. The assay successfully detected and identified the fungal pathogen in $\mathbf{9 3 . 6 \%}$ and $64.3 \%$ of culture-proven and solely histologically proven cases of IFI, respectively. A diverse range of fungal genera were identified, including species of Candida, Cryptococcus, Trichosporon, Aspergillus, Fusarium, Scedosporium, Exophiala, Exserohilum, Apophysomyces, Actinomucor, and Rhizopus. For five specimens, molecular analysis identified a pathogen closely related to that identified by culture. All PCR-negative specimens $(n=10)$ were PE tissues in which fungal hyphae were visualized. The results support the use of the panfungal PCR assay in combination with conventional laboratory tests for accurate identification of fungi in tissue specimens.
\end{abstract}

The frequency of invasive fungal infections (IFIs) in critically ill and immunocompromised patients is continuing to increase. Epidemiological studies now indicate that the spectrum of fungal pathogens has expanded well beyond Aspergillus fumigatus and Candida species (28). Contributory factors include an increase in the patient population at risk of IFI, better appreciation that unusual fungi can cause disease, and selection pressures from current practices of antifungal use $(8,28)$. Early, rapid, and accurate identification of pathogenic fungi is important in order to guide the selection of appropriate antifungal therapy and thus improve patient outcomes, as well as for epidemiologic purposes (17). However, current culture-based phenotypic methods are insensitive and slow, may initially be nonspecific, and require considerable expertise for correct morphological identification of less common or unusual fungi $(1,5)$. Additional drawbacks of conventional culture include the failure of zygomycetes to grow when hyphal cells have been damaged during processing (21) and the collection of tissue biopsy specimens directly into formalin fixative for paraffin embedding when IFIs are not suspected clinically (19) or when limited material is available.

Recent efforts to improve the sensitivity and specificity of diagnostic tests have focused on culture-independent methods, in particular nucleic acid-based methods, such as PCR assays. These can be applied to fresh and formalin-fixed, paraffinembedded (PE) sections. Numerous studies have highlighted the

\footnotetext{
* Corresponding author. Mailing address: Centre for Infectious Diseases and Microbiology, Westmead Hospital, Westmead, New South Wales, 2145, Australia. Phone: 61-2-9845 6255. Fax: 61-2-9893 8659. E-mail: catrionah@icpmr.wsahs.nsw.gov.au.

${ }^{\nabla}$ Published ahead of print on 22 November 2006.
}

advantages of using PCR technology to detect viable and nonviable fungal pathogens in a variety of clinical specimens. The majority of assays target multicopy genes, in particular the ribosomal DNA (rDNA) genes (18S, 28S, and 5.8S) and the intervening internal transcribed spacer (ITS) regions (ITS1 and ITS2), in order to maximize sensitivity and specificity. To date, most assays have been designed to detect Candida or Aspergillus species only $(14,16,17,22,24,35,38,39,43)$. Given that more than 200 fungal species have been reported to cause disease in humans and companion animals (11), the clinical utility of a species-specific or even a genus-specific assay is limited. Panfungal PCR assays, on the other hand, have the potential to detect all fungal species, but many rely on additional, time-consuming techniques, such as species-specific probes and hybridization, to identify the pathogen $(10,12,15,25,29,34,37)$. Furthermore, probe design is restricted to known pathogens and does not allow the identification of new and emerging agents. Sequence-based identification of PCR products is a sensitive alternative, provided that accurate sequences have been submitted to public databases, e.g., GenBank $(5,32,42)$.

In this study, we developed and evaluated a panfungal PCR assay to detect and identify fungal pathogens directly from fresh and PE tissue specimens obtained from patients with culture-proven and/or histologically proven IFIs. We chose to target the ITS1 region, located between the 18S and 5.8S rRNA genes, because (i) it is multicopy ( $\geq 100$ copies in the fungal genome), (ii) universal fungal primers are available, and (iii) it contains highly variable regions for species identification $(6,15,17,18,20,23,24,26)$, and we used DNA sequence analysis for species identification. The 
results of the molecular identification were correlated with those obtained by histological examination and culture.

\section{MATERIALS AND METHODS}

Clinical specimens. Seventy-five tissue specimens from 62 patients ( 43 humans and 19 companion animals) with culture-proven $(n=38)$ (see Table 1$)$ and histologically documented but culture-negative $(n=24)$ (see Table 2) IFIs were evaluated using the panfungal PCR assay. In cases of culture-positive IFI, the species was identified by standard phenotypic and morphological characteristics $(9,21)$. Specimens were obtained from a variety of body sites, including both sterile and nonsterile locations; 37 were fresh tissue biopsy specimens, and 38 were PE (see Tables 1 and 2). In addition, we tested a skin biopsy specimen from a patient with disseminated nodular skin lesions, where there was a high index of suspicion for IFI (patient 63) but culture and histology results were negative. Fresh $(n=14)$ and PE $(n=4)$ tissue specimens from a variety of body sites (brain, skin and soft tissue, eye, bone, lung, cardiac valve, and bone marrow) from 12 patients without IFIs were used as controls.

DNA extraction. Specimen manipulations and DNA extractions were performed in a class II laminar flow cabinet. For each PE tissue sample, 10 sections (thickness, $10 \mu \mathrm{m}$ ) were cut using a sterile microtome blade and transferred to a 10-ml centrifuge tube (Sarstedt Australia, Technology Park, Australia). To remove paraffin wax, $5 \mathrm{ml}$ of histolene (Fronine Laboratory Supplies, Riverstone, Australia) was added, mixed by inversion, incubated at room temperature overnight, and centrifuged (at 3,838 $\times g$ for $15 \mathrm{~min}$ ) in a Beckman Coulter (Fullerton, CA) GS-15 centrifuge. The supernatant was removed, and the pellet was washed with $5 \mathrm{ml}$ of $100 \%$ ethanol (Ajax Finechem, Seven Hills, Australia), mixed by inversion, and centrifuged (at 3,838 $\times g$ for $15 \mathrm{~min}$ ). The tissue pellet was transferred to a 2-ml microcentrifuge tube (Eppendorf AG, Hamburg, Germany) and washed in $1 \mathrm{ml}$ of $100 \%$ ethanol, followed by $1 \mathrm{ml}$ of $70 \%$ ethanol. The ethanol was removed by centrifugation (at 5,900 $\times g$ for $10 \mathrm{~min}$ ), and the pellet was air dried at room temperature in preparation for DNA extraction. For DNA extraction, all tissue samples were incubated for $\geq 3 \mathrm{~h}$ in proteinase $\mathrm{K}$ and lysis buffer at $55^{\circ} \mathrm{C}$, and the DNA was extracted using the MagNAPure LC instrument with the MagNAPure LC DNA isolation kit II (Tissue) (Roche Diagnostics, Mannheim, Germany) according to the manufacturer's instructions. The DNA was stored at $-20^{\circ} \mathrm{C}$ prior to use. To monitor contamination, each specimen was shadowed by a negative control containing molecular-biology-grade water (Eppendorf AG).

PCR amplification and DNA sequencing. PCRs were performed in a $25-\mu \mathrm{l}$ volume consisting of $1 \times$ PCR buffer $(10 \mathrm{mM}$ Tris- $\mathrm{HCl}$ [pH 8.3], $50 \mathrm{mM} \mathrm{KCl}, 1.5$ $\mathrm{mM} \mathrm{MgCl} 2$, and $0.001 \%$ gelatin) (Applied Biosystems, Foster City, CA), $2 \mathrm{mM}$ $\mathrm{MgCl}_{2}$ solution (Roche Diagnostics), $5 \%$ glycerol (Sigma Chemical Co., St. Louis, MO), $0.25 \mathrm{mM}$ deoxynucleoside triphosphates (Roche Diagnostics), 0.8 $\mu \mathrm{M}$ primers ITS 1 (5'-TCC GTA GGT GAA CCT GCG G) and ITS 2 (5'-GCT GCG TTC TTC ATC GAT GC) (40) (Sigma-Genosys, Australia), $1.25 \mathrm{U}$ of AmpliTaq Gold DNA polymerase (Applied Biosystems), and $10 \mu$ l of DNA. Amplification was performed on a Mastercycler gradient thermocycler (Eppendorf AG). The thermal cycling conditions were $95^{\circ} \mathrm{C}$ for $10 \mathrm{~min}$, followed by 60 cycles of $94^{\circ} \mathrm{C}$ for $15 \mathrm{~s}, 55^{\circ} \mathrm{C}$ for $30 \mathrm{~s}$, and $72^{\circ} \mathrm{C}$ for $30 \mathrm{~s}$, and a final extension at $72^{\circ} \mathrm{C}$ for $5 \mathrm{~min}$. A negative control of molecular-biology-grade water and an inhibition control composed of an equal mixture of specimen DNA and Candida parapsilosis (strain no. ATCC 22019) positive-control DNA were included for each specimen. The inhibition control was used to exclude the presence of inhibitory substances. PCR products were separated by $1.5 \%$ agarose gel electrophoresis, stained with SYBR Safe DNA gel stain (Molecular Probes, Eugene, OR), and visualized by UV light transillumination. PCR products were purified using the GFX PCR DNA and gel band purification kit (Amersham Biosciences, Castle Hill, Australia) and were sequenced using the ITS 1 primer and the BigDye Terminator (version 3.1) cycle sequencing kit in the ABI PRISM 3100 genetic analyzer (Applied Biosystems). Sequences were edited using Chromas (version 2.23) software (Technelysium Pty. Ltd.) and entered into a BLASTN sequence analysis search (2) provided by BioManager, ANGIS (http://www.angis .org.au), for species identification.

Contamination control. Prior to any experimental procedure, all work surfaces and equipment, including cabinets, pipettes, and racks, were wiped down with NucleoClean decontamination solution (Chemicon International, Temecula, CA). DNA extraction, PCR setup, PCR amplification, and agarose gel electrophoresis were performed in separate, independently equipped laboratories, set out in a unidirectional workflow to prevent carryover contamination. PCR master mixes were prepared using a PCR cabinet cleaned with $70 \%$ alcohol and UV irradiated for $20 \mathrm{~min}$, positive-displacement pipettes, and aerosol-resistant pipette tips.

\section{RESULTS}

Specimens from patients without IFIs. No fungal DNA was amplified from 18 control tissue specimens obtained from 12 patients without IFIs.

Specimens from patients with culture-proven IFIs. Thirtyone fresh and $16 \mathrm{PE}$ tissue specimens from 38 patients with culture-proven IFIs were tested. Patients were infected with a diverse range of yeasts and molds, including the uncommon pathogens Metarhizium anisopliae and Microsphaeropsis arundinis (Table 1). A PCR product was obtained from each specimen; however, DNA sequencing was unsuccessful for three (patients 36 to 38). For two of these, DNA was extracted from PE sections in which only scant fungal hyphae were seen upon histological examination. For the remaining specimen (patient 37), multiple bands were present on the gel, suggesting a mixed fungal infection; however, a single isolate recovered by culture was identified as Glomerella lagenaria by ITS sequence analysis.

Sequencing results correlated with culture identification for 39 of $44(88.6 \%)$ specimens (Table 1$)$. For the remaining five specimens, analysis yielded sequences with 98 to $100 \%$ identity to sequences of fungi that are phylogenetically closely related to the species identified by culture-based methods (given in parentheses): patient 18, Neosartorya pseudofischeri (Aspergillus fumigatus); patient 27, Exophiala spinifera (Exophiala jeanselmei); patient 35, Rhizomucor pusillus (Absidia corymbifera) (Table 1). Forty-one of $44(93.2 \%)$ sequences showed $\geq 98 \%$ identity to sequences deposited in the GenBank database. The other three demonstrated 96 to $97 \%$ identity. Sequence analysis of the ITS1 region was unable to differentiate between members of the Cryptococcus neoformans complex (Cryptococcus gattii, Cryptococcus neoformans var. neoformans, and Cryptococcus neoformans var. grubii); Fusarium species, including Fusarium verticillioides, $F$. subglutinans, and $F$. proliferatum; Neosartorya spp. and Aspergillus lentulus; Rhizopus oryzae and Amylomyces rouxii; and Exserohilum rostratum and Exserohilum mcginnisii.

Specimens from patients with histologically proven IFIs. Six fresh and $22 \mathrm{PE}$ tissue specimens from 24 patients with histologically proven IFIs were analyzed by PCR. Nine of these specimens (six patients) were obtained at postmortem examination. Fungal DNA was amplified from 18 (64.3\%) samples, and DNA sequencing identified a variety of fungal pathogens, including Candida spp., Trichosporon spp., Aspergillus spp., and zygomycetes (Table 2). With the exception of one specimen (patient 51), sequence analysis showed $\geq 98 \%$ identity to sequences in the GenBank database. The molecular identification was consistent with the histological diagnosis in 17 of 18 $(94.4 \%)$ cases. The exception was patient 40 , where C. parapsilosis DNA was detected in a nasopharyngeal biopsy specimen but histopathology (showing narrow-necked budding, encapsulated yeasts) was consistent with a $C$. neoformans complex infection. All of the PCR-negative specimens $(n=10)$ were PE sections; six of these (patients 59 to 62) had morphological characteristics indicative of a zygomycete, while scant fungal elements were seen in three of the remaining four (patients 56 to 58). Cryptococcus albidus and Cryptococcus albidosimilis (patient 41) were not distinguished by sequence analysis of the ITS1 region. 
TABLE 1. Results of culture, PCR, and DNA sequence analysis of tissue samples from patients with culture-proven IFIs ${ }^{a}$

\begin{tabular}{|c|c|c|c|c|c|c|}
\hline Patient & $\begin{array}{c}\text { Tissue site } \\
\text { (type of specimen) }\end{array}$ & Clinical diagnosis & Identification by culture & $\begin{array}{l}\text { Histology } \\
\text { result }\end{array}$ & $\begin{array}{l}\text { PCR } \\
\text { result }\end{array}$ & $\begin{array}{l}\text { Molecular identification } \\
\text { (\% identity with } \\
\text { GenBank sequence) }\end{array}$ \\
\hline 1 & Vocal cord $(\mathrm{F})$ & IC & Candida albicans & NP & + & C. albicans (99) \\
\hline 2 & Thigh $(F)$ & IC & C. albicans & NP & + & C. albicans (99) \\
\hline 3 & Skin $(F)$ & IC & Candida glabrata & + & + & C. glabrata (98) \\
\hline 4 & Urinary bladder $(\mathrm{F})$ & IC & Candida krusei & - & + & C. krusei (99) \\
\hline 5 & Carotid artery $(\mathrm{F})$ & IC & Candida tropicalis & + & + & C. tropicalis $(100)$ \\
\hline $6^{b}$ & Skin $(\mathrm{PE})$ & Cryptococcosis & Cryptococcus gattii & + & + & C. neoformans/C. gattii (99) \\
\hline 7 & Lung (F) & Cryptococcosis & Cryptococcus neoformans & NP & + & C. neoformans/C. gattii (100) \\
\hline 8 & Nasal mucosa $(\mathrm{F})$ & Cryptococcosis & C. neoformans & + & + & C. neoformans/C. gattii (99) \\
\hline $9^{b}$ & Nasal cavity (PE) & Cryptococcosis & C. neoformans & + & + & C. neoformans/C. gattii (98) \\
\hline 10 & Paranasal sinus $(\mathrm{F})$ & IA & Aspergillus flavus & - & + & A. flavus (99) \\
\hline 11 & Lung $(\mathrm{F})$ & IA & Aspergillus fumigatus & + & + & A. fumigatus (100) \\
\hline 12 & Nasal mucosa $(\mathrm{F})$ & IA & A. fumigatus & + & + & A. fumigatus (99) \\
\hline $13^{b}$ & Nasal cavity (F) & IA & A. fumigatus & + & + & A. fumigatus (100) \\
\hline $14^{b}$ & Frontal sinus $(\mathrm{F})$ & IA & A. fumigatus & - & + & A. fumigatus (99) \\
\hline $15^{b}$ & Nasal cavity (PE) & IA & Aspergillus spp. & + & + & A. fumigatus (100) \\
\hline $16^{b}$ & Air sac (PE) & IA & A. fumigatus & + & + & A. fumigatus (100) \\
\hline $17^{b}$ & Paranasal sinus $(\mathrm{PE})$ & IA & A. fumigatus & + & + & A. fumigatus (100) \\
\hline $18 \mathrm{~A}^{b}$ & Retrobulbar space $(\mathrm{F})$ & IA & A. fumigatus & + & + & Neosartorya pseudofischeri $(100)$ \\
\hline $18 \mathrm{~B}^{b}$ & Retrobulbar space (PE) & IA & A. fumigatus & + & + & N. pseudofischeri (100) \\
\hline $18 C^{b}$ & Retrobulbar space $(\mathrm{F})$ & IA & A. fumigatus & + & + & N. pseudofischeri (98) \\
\hline 19 & Sinus $(F)$ & IFI & A. fumigatus & + & + & A. fumigatus (100) \\
\hline $20 \mathrm{~A}$ & Lung (F) & IFI & A. fumigatus & + & + & A. fumigatus (100) \\
\hline 20B & Spleen $(F)$ & IFI & A. fumigatus & - & + & A. fumigatus (99) \\
\hline 21 & Brain $(\mathrm{F})$ & IFI & A. fumigatus & + & + & A. fumigatus (99) \\
\hline $22 \mathrm{~A}$ & Lung (PE) & IFI & $\begin{array}{l}\text { Neosartorya spp./Aspergillus } \\
\text { lentulus }\end{array}$ & + & + & Neosartorya spp./A. lentulus (99) \\
\hline 22B & Lung $(\mathrm{F})$ & IFI & Neosartorya spp./A. lentulus & + & + & Neosartorya spp./A. lentulus (99) \\
\hline $22 \mathrm{C}$ & Lung $(\mathrm{F})$ & IFI & Neosartorya spp./A. lentulus & + & + & Neosartorya spp./A. lentulus (99) \\
\hline $23^{b}$ & Abdominal mass (PE) & IFI & Scedosporium apiospermum & + & + & S. apiospermum (99) \\
\hline 24 & Costal cartilage $(\mathrm{F})$ & IFI & Scedosporium prolificans & - & + & S. prolificans (99) \\
\hline 25 & Skin (PE) & Fusariosis & Fusarium spp. & + & + & Fusarium spp. $(99)^{c}$ \\
\hline 26 & Synovial fluid (F) & IFI & Exophiala spp. & NP & + & Exophiala spp. (97) \\
\hline $27^{b}$ & Skin (PE) & Dematiaceous IFI & Exophiala jeanselmei & + & + & Exophiala spinifera (98) \\
\hline $28^{b}$ & Skin (PE) & IFI & E. jeanselmei & + & + & Exophiala spp. (99) \\
\hline 29 & Nasal mucosa $(\mathrm{F})$ & IFI & Exserohilum rostratum & + & + & $\begin{array}{l}\text { E. rostratum/Exserohilum } \\
\text { mcginnisii (99) }\end{array}$ \\
\hline $30^{b}$ & Nasal bones (PE) & IFI & Metarhizium anisopliae & + & + & M. anisopliae (99) \\
\hline $31^{b}$ & Nasal cavity (PE) & IFI & Microsphaeropsis arundinis & + & + & M. arundinis (100) \\
\hline $32 \mathrm{~A}$ & Buttock (F) & Zygomycosis & Apophysomyces elegans & + & + & Apophysomyces elegans (96) \\
\hline 32B & Buttock $(\mathrm{F})$ & Zygomycosis & Apophysomyces elegans & + & + & Apophysomyces elegans (97) \\
\hline $33 \mathrm{~A}$ & Paranasal sinus $(\mathrm{F})$ & Zygomycosis & Rhizopus spp. & + & + & $\begin{array}{l}\text { Rhizopus oryzae/Amylomyces } \\
\text { rouxii }(99)\end{array}$ \\
\hline $33 \mathrm{~B}$ & Paranasal sinus $(\mathrm{F})$ & Zygomycosis & Rhizopus spp. & + & + & R. oryzae/A. rouxii (98) \\
\hline $33 \mathrm{C}$ & Paranasal sinus (F) & Zygomycosis & Rhizopus spp. & + & + & R. oryzae/A. rouxii (99) \\
\hline 33D & Paranasal sinus (F) & Zygomycosis & Rhizopus spp. & + & + & R. oryzae/A. rouxii (99) \\
\hline 34 & Paranasal sinus $(\mathrm{F})$ & Zygomycosis & R. oryzae & + & + & R. oryzae/A. rouxii (100) \\
\hline $35^{b}$ & Nasal turbinate (PE) & Zygomycosis & Absidia corymbifera & + & + & Rhizomисоr pusillus (99) \\
\hline $36^{b}$ & Nasal cavity (PE) & IA & A. fumigatus & + & + & No result \\
\hline $37^{b}$ & Flank (F) & IFI & Glomerella lagenaria & + & + & No result \\
\hline $38^{b}$ & Eye (PE) & Cryptococcosis & C. neoformans & + & + & No result \\
\hline
\end{tabular}

${ }^{a} \mathrm{~F}$, fresh tissue; PE, paraffin embedded; IA, invasive aspergillosis; IC, invasive candidiasis; NP, histology not performed.

${ }^{b}$ Specimen from animal patient.

${ }^{c}$ Differentiation of Fusarium species by ITS sequence analysis is complicated by the presence of $>1$ ITS sequence variant in a single strain (27).

Specimen from a patient with a suspected IFI. PCR and DNA sequence analysis of a skin biopsy specimen from patient 63 identified the causative pathogen as Trichophyton verrucosum, with $100 \%$ identity to $T$. verrucosum sequences in the GenBank database.

\section{DISCUSSION}

Rapid and precise identification of fungal pathogens to species level is critical to improving the management of IFIs. The results from this study indicate that the application of a panfungal PCR to amplify the ITS1 region of the rDNA gene cluster followed by DNA sequencing is a highly sensitive and useful tool for the detection and identification of a wide range of fungi from both fresh (>97\% sensitivity) and PE $(68 \%$ sensitivity) tissue specimens.

The validity and clinical applicability of the assay were confirmed by testing specimens from patients with culture-proven IFIs (Table 1). Although the PCR amplified fungal DNA for 
TABLE 2. Results of histology, PCR, and DNA sequence analysis of tissue samples from patients with histologically proven IFIs

\begin{tabular}{|c|c|c|c|c|c|}
\hline Patient & Tissue site ${ }^{a}$ & Clinical diagnosis ${ }^{b}$ & $\begin{array}{l}\text { Historical characteristic } \\
(\text { estimate of quantity })\end{array}$ & $\begin{array}{l}\text { PCR } \\
\text { result }\end{array}$ & $\begin{array}{c}\text { Molecular identification } \\
\text { (\% identity with GenBank sequence) }\end{array}$ \\
\hline 39 & Liver $(F)$ & IFI & Pseudohyphae $(+++)$ & + & Candida dubliniensis (99) \\
\hline $40^{d}$ & Nasopharynx (PE) & Cryptococcosis & $\begin{array}{l}\text { Yeast-like organisms with capsule and } \\
\text { narrow-necked budding }(++)\end{array}$ & + & Candida parapsilosis (98) \\
\hline 41 & Neck (PE) & IFI & $\begin{array}{l}\text { Yeast-like organisms with capsule } \\
(++)\end{array}$ & + & $\begin{array}{l}\text { Cryptococcus albidus/Crypotococcus } \\
\text { albidosimilis (99) }\end{array}$ \\
\hline $42 \mathrm{~A}$ & $\begin{array}{l}\text { PM pericardium } \\
(\mathrm{PE})\end{array}$ & IFI & Prominent hyphae $(+++)$ & + & Trichosporon asahii (100) \\
\hline $42 \mathrm{~B}$ & PM kidney (PE) & IFI & Prominent hyphae $(+++)$ & + & T. asahii (99) \\
\hline 43 & Muscle (F) & IFI & Yeast-like organisms $(+++)$ & + & Trichosporon cutaneum (99) \\
\hline 44 & PM lung (PE) & IA & Septate branching hyphae $(+++)$ & + & A. fumigatus (100) \\
\hline 45 & PM lung (PE) & IA & Septate branching hyphae $(+++)$ & + & A. fumigatus (100) \\
\hline 46 & Lung $(\mathrm{F})$ & IFI & Septate branching hyphae $(+++)$ & + & A. fumigatus (100) \\
\hline 47 & Lung $(\mathrm{F})$ & IA & Septate branching hyphae $(+++)$ & + & A. fumigatus (99) \\
\hline 48 & Lung (PE) & IFI & Septate branching hyphae $(+++)$ & + & A. fumigatus (99) \\
\hline $49^{d}$ & Paranasal sinus $(\mathrm{PE})$ & IFI & Fungal elements $(+++)$ & + & $\begin{array}{l}\text { Neosartorya spp./Aspergillus } \\
\text { lentulus (100) }\end{array}$ \\
\hline 50 & Brain $(F)$ & IFI & Branching, septate hyphae $(++)$ & + & Neosartorya spp./A. lentulus (99) \\
\hline 51 & Knee biopsy $(\mathrm{F})$ & IFI & Fungal elements $(+)$ & + & Phoma spp. (97) \\
\hline $52 \mathrm{~A}$ & PM large bowel (PE) & IFI & Broad, irregular aseptate hyphae $(++)$ & + & Apophysomyces elegans (98) \\
\hline $52 \mathrm{~B}$ & PM liver (PE) & IFI & Broad, irregular aseptate hyphae $(++)$ & + & Apophysomyces elegans (98) \\
\hline 53 & Nasal mucosa (PE) & Zygomycosis & Broad, irregular aseptate hyphae $(++)$ & + & Actinomucor elegans (99) \\
\hline 54 & PM lung (PE) & Zygomycosis & Broad, irregular aseptate hyphae $(++)$ & + & Rhizopus microsporus (99) \\
\hline 55 & Unspecified (PE) & Coccidioidomycosis & Unknown & - & - \\
\hline 56 & Lung (PE) & Histoplasmosis & Intracellular yeast (+) & - & - \\
\hline 57 & Skin (PE) & Penicilliosis marneffei & Intracellular fungal elements $(+)$ & - & - \\
\hline 58 & Nasal mucosa (PE) & IFI & Hyphae and spores $(+)$ & - & - \\
\hline $59 \mathrm{~A}$ & $\mathrm{PM}$ brain $(\mathrm{PE})$ & IFI & $\begin{array}{l}\text { Broad, irregular aseptate hyphae } \\
(+++)\end{array}$ & - & - \\
\hline 59B & $\mathrm{PM}$ brain $(\mathrm{PE})$ & IFI & $\begin{array}{l}\text { Broad, irregular aseptate hyphae } \\
(+++)\end{array}$ & - & - \\
\hline 60 & $\begin{array}{l}\text { Pterygopalatine fossa } \\
\text { (PE) }\end{array}$ & IFI & Broad aseptate hyphae $(++)$ & - & - \\
\hline 61 & Lung (PE) & IFI & $\begin{array}{l}\text { Moderately thick branching hyphae } \\
(++)\end{array}$ & - & - \\
\hline $62 \mathrm{~A}$ & Paranasal sinus (PE) & IFI & Broad, irregular aseptate hyphae $(++)$ & - & - \\
\hline $62 \mathrm{~B}$ & Paranasal sinus (PE) & IFI & Fungal elements $(++)$ & - & - \\
\hline
\end{tabular}

\footnotetext{
${ }^{a} \mathrm{~F}$, fresh tissue; PM, postmortem examination specimen; PE, paraffin embedded.

${ }^{b} \mathrm{IA}$, invasive aspergillosis.

$c+++$, numerous; ++ , moderate; + , scant

${ }^{d}$ Specimen from animal patient.
}

all 47 culture-positive specimens, DNA sequencing was unsuccessful in 3 cases. In one case, this was probably due to the presence of mixed fungal species, since multiple bands were present on the gel. In the other two, insufficient DNA may have been extracted from the paraffin sections, or nonspecific PCR products may have been generated.

Comparative sequence analysis confirmed the conventional culture-based identification for 39 of the 44 (88.6\%) remaining specimens. Discordant results were observed for five specimens from three patients (Table 1). The cultures of three retrobulbar specimens from one patient yielded $A$. fumigatus by conventional identification, but subsequent DNA sequence analysis of the complete ITS region identified the culture as $N$. pseudofischeri. Although genetically distinct, the asexual state of $N$. pseudofischeri (and the closely related Neosartorya fischeri) is morphologically similar to A. fumigatus. Until recently, Neosartorya spp. have rarely been reported to have caused disease, although the difficulty in morphologically distinguishing $A$. fumigatus from Neosartorya spp. may have led to underestimation of the frequency of infection caused by the latter (3). Accurate identification is clinically important, since it has been reported that Neosartorya spp. are less susceptible in vitro to antifungal agents than $A$. fumigatus (3).

For the second patient, molecular analysis of the fungal pathogen from a skin biopsy specimen (PE) identified it as Exophiala spinifera, while the isolate was identified morphologically from culture of fresh tissue as Exophiala jeanselmei. Comparison of ITS1 sequences of multiple strains of E. spinifera and E. jeanselmei deposited in GenBank revealed that the two species can be distinguished easily. The isolate from patient 27 showed $98 \%$ sequence identity to six E. spinifera strains from the Centraalbureau voor Schimmelcultures. The variable morphological characteristics of Exophiala spp. make definitive identification difficult; as a result, molecular analyses are increasingly used for species confirmation (30).

PCR amplification and DNA sequencing twice identified the fungal pathogen from a nasal turbinate biopsy specimen (PE) from the third patient as Rhizomucor pusillus rather than Absidia corymbifera. Although these two organisms share antigenic similarities, they are morphologically distinct, and comparison of their ITS1 sequences reveals substantial differences (33). Given that the organism was isolated by another labora- 
tory in 1992, it was not possible to check the details of the original identification, but it is likely to be a case of misidentification.

The panfungal PCR assay performed well on specimens where fungal elements were visualized but no pathogen was grown. A molecular identification could be assigned to 18 of 28 $(64.3 \%)$ specimens, including all 5 fresh specimens, and the identification was consistent with the histological findings for all but 1 . In this case, $C$. parapsilosis DNA was detected from a nasopharyngeal biopsy specimen, but histologically the pathogen was identified as $C$. neoformans complex. It is likely that $C$. parapsilosis was present as a commensal, rather than as the infecting agent, in the nasopharynx of this patient and was amplified by the PCR assay. This case and those reported by others (42) demonstrate that the application of a sensitive, broad-range nucleic acid test to specimens from nonsterile sites should always be interpreted in the appropriate clinical context. The PCR was negative for 10 specimens from eight patients with histologically proven IFIs (Table 2, patients 55 to 62). Since all of these specimens were PE, the quality of DNA is likely to have been compromised by the routine processes required for histological examination, in particular the duration of contact with formalin fixative prior to paraffin embedding (41, 42). Additionally, insufficient amounts of DNA may have been present for detection by PCR, since at least three of the specimens had scant fungal elements upon histological examination (Table 2).

DNA sequencing proved useful in two additional clinical contexts. First, tissue obtained at autopsy, where IFI is not clinically suspected antemortem, is frequently not submitted for culture. In our study, the fungal pathogen was identified by PCR and DNA sequencing in specimens obtained at postmortem examination from five of six patients (Table 2). Second, for a patient with follicular skin lesions for whom fungal infection was suspected, the diagnosis of $T$. verrucosum infection achieved in the absence of either culture or histology results was central to selecting appropriate antifungal therapy.

Studies have demonstrated that the most promising targets for molecular identification of fungi are the ITS1 and/or the ITS2 region, followed by the D1-D2 region of the large-subunit DNA gene (28S rDNA) $(7,17,23,31)$. For this reason, we targeted the ITS1 region. Nevertheless, our results indicate that there is insufficient sequence variation to differentiate between species of certain genera by using the ITS1 region alone (e.g., C. neoformans complex, C. albidus and C. albidosimilis, Neosartorya spp. and $A$. lentulus, and Fusarium spp.). These results were not unexpected, since it has been reported that ITS sequence variations among some species of fungi, including Aspergillus spp., are minimal (13, 17, 19, 36), and the differentiation of Fusarium species is complicated by the presence of $>1$ ITS sequence variant in a single strain (27). For those species that cannot be discriminated using the ITS1 region alone, future work may involve sequence analysis of additional genes, such as ITS2, the D1-D2 region of $28 \mathrm{~S}$ rDNA, or intergenic spacer regions (19).

Despite the usefulness of the panfungal PCR assay for the identification of fungal pathogens in histologically positive but culture-negative tissue specimens, the limitations of the assay must also be considered. Environmental contamination of specimens and/or the PCR master mixture by ubiq- uitous fungal spores is a possible cause of "false-positive" results in a sensitive, broad-range PCR assay. This was not likely to have occurred in the present study, because strict precautions were taken throughout the whole procedure, including processing each specimen with its own negative control during DNA extraction and PCR amplification and performing all procedures using a unidirectional workflow pattern. The turnaround time for results is realistically a minimum of $48 \mathrm{~h}$ for fresh specimens and 4 to 5 days for PE sections. Two working days are required to remove the wax from PE tissue specimens, and one working day is required to extract the DNA and perform PCR amplification and product detection. Additionally, we rely on an external DNA sequencing facility, and its turnaround time is 24 to $48 \mathrm{~h}$. Importantly, accurate sequence-based identification of fungal pathogens is dependent on the quality and accuracy of sequences in existing databases. GenBank sequence submissions are not peer reviewed, and it has been estimated that 10 to $20 \%$ of fungal sequences in GenBank are misidentified organisms (4; R. Summerbell, presented at the 16th Congress of the International Society for Human and Animal Mycology, 2006). Given that in our study, the molecular identification was consistent with the histological diagnosis for 17 of 18 specimens for which histology only was positive, the inaccuracy of some GenBank entries should not have affected our results. However, the development of an accurate sequence database for fungal species would be beneficial for this assay.

In conclusion, this study illustrates the potential benefits of using the panfungal PCR assay in combination with conventional laboratory tests for sensitive and specific identification of fungal pathogens in both fresh and PE tissue specimens. For rapid diagnosis of IFIs from fresh tissue, we recommend that the panfungal PCR be performed as soon as fungal elements are seen on microscopy. For PE specimens, we envisage the assay to be most valuable in cases where fungal hyphae are visualized and where either the culture result is negative or culture is not performed. Evaluation of the panfungal PCR assay on specimens from other sterile body sites, e.g., blood, is indicated.

\section{ACKNOWLEDGMENTS}

We thank Orla Morrissey, Simon Iles, Jeff Szer, Ivan Stratov, Monica Slavin, Chris Blyth, Matthew O'Sullivan, Hema Mahajan, Debbie Marriott, Jenny Robson, Mark Krockenberger, and Vanessa Barrs for referring specimens.

This work was supported in part by a Centre of Clinical Excellence grant (264625) from the National Health and Medical Research Council of Australia. A.L. is supported by an Australian Universities Postgraduate student award.

\section{REFERENCES}

1. Alexander, B. D., and M. A. Pfaller. 2006. Contemporary tools for the diagnosis and management of invasive mycoses. Clin. Infect. Dis. 43:S15S27.

2. Altschul, S. F., T. L. Madden, A. A. Schäffer, J. Zhang, Z. Zhang, W. Miller, and D. J. Lipman. 1997. Gapped BLAST and PSI-BLAST: a new generation of protein database search programs. Nucleic Acids Res. 25:3389-3402.

3. Balajee, S. A., J. Gribskov, M. Brandt, J. Ito, A. Fothergill, and K. A. Marr. 2005. Mistaken identity: Neosartorya pseudofischeri and its anamorph masquerading as Aspergillus fumigatus. J. Clin. Microbiol. 43:5996-5999.

4. Bruns, T. D., and R. P. Shefferson. 2004. Evolutionary studies of ectomycorrhizal fungi: recent advances and future directions. Can. J. Bot. 82:11221132 . 
5. Chen, S. C. A., C. L. Halliday, and W. Meyer. 2002. A review of nucleic acid-based diagnostic tests for systemic mycoses with an emphasis on polymerase chain reaction-based assays. Med. Mycol. 40:333-357.

6. Chen, Y.-C., J. D. Eisner, M. M. Kattar, S. L. Rassoulian-Barrett, K. Lafe, U. Bui, A. P. Limaye, and B. T. Cookson. 2001. Polymorphic internal transcribed spacer region 1 DNA sequences identify medically important yeasts. J. Clin. Microbiol. 39:4042-4051.

7. Ciardo, D. E., G. Schar, E. C. Bottger, M. Altwegg, and P. P. Bosshard. 2006 Internal transcribed spacer sequencing versus biochemical profiling for identification of medically important yeasts. J. Clin. Microbiol. 44:77-84.

8. Cordonnier, C. 2004. Fungal infections: current diagnosis and treatment. Hematol. J. 5(Suppl. 3):S59-S62.

9. de Hoog, G. S., J. Guarro, J. Gene, and M. J. Figueras. 2000. Atlas of clinical fungi, 2nd ed. Centraalburearu voor Schimmelcultures/Universitat Rovia Virgili, Utrecht, The Netherlands.

10. Einsele, H., H. Hebart, G. Roller, J. Loffler, I. Rothenhofer, C. A. Muller, R. A. Bowden, J.-A. van Burik, D. Engelhard, L. Kanz, and U. Schumacher. 1997. Detection and identification of fungal pathogens in blood by using molecular probes. J. Clin. Microbiol. 35:1353-1360.

11. Ellis, D. 2002. Amphotericin B: spectrum and resistance. J. Antimicrob. Chemother. 49(Suppl. 1):7-10.

12. Evertsson, U., H. J. Monstein, and A. G. Johansson. 2000. Detection and identification of fungi in blood using broad-range 28S rDNA PCR amplification and species-specific hybridisation. APMIS 108:385-392.

13. Gaskell, G. J., D. A. Carter, W. J. Britton, E. R. Tovey, F. H. L. Benyon, and Y. Lovborg. 1997. Analysis of the internal transcribed spacer regions of ribosomal DNA in common airborne allergenic fungi. Electrophoresis 18: 1567-1569.

14. Halliday, C., R. Hoile, T. Sorrell, G. James, S. Yadav, P. Shaw, M. Bleakley, K. Bradstock, and S. Chen. 2006. Role of prospective screening of blood for invasive aspergillosis by polymerase chain reaction in febrile neutropenic recipients of haematopoietic stem cell transplants and patients with acute leukaemia. Br. J. Haematol. 132:478-486.

15. Hendolin, P. H., P. Lars, P. Koukila-Kahkola, V. J. Anttila, H. Malmberg, M. Richardson, and J. Ylikoski. 2000. Panfungal PCR and multiplex liquid hybridization for detection of fungi in tissue specimens. J. Clin. Microbiol. 38:4186-4192.

16. Henry, T., P. C. Iwen, and S. H. Hinrichs. 2000. Identification of Aspergillus species using internal transcribed spacer regions 1 and 2. J. Clin. Microbiol. 38:1510-1515.

17. Hinrikson, H. P., S. F. Hurst, T. J. Lott, D. W. Warnock, and C. J. Morrison. 2005. Assessment of ribosomal large-subunit D1-D2, internal transcribed spacer 1, and internal transcribed spacer 2 regions as targets for molecular identification of medically important Aspergillus species. J. Clin. Microbiol. 43:2092-2103.

18. Hsiao, C. R., L. Huang, J. P. Bouchara, R. Barton, H. C. Li, and T. C. Chang. 2005. Identification of medically important molds by an oligonucleotide array. J. Clin. Microbiol. 43:3760-3768.

19. Iwen, P. C., S. H. Hinrichs, and M. E. Rupp. 2002. Utilization of the internal transcribed spacer regions as molecular targets to detect and identify human fungal pathogens. Med. Mycol. 40:87-109.

20. Kumar, M., and P. K. Shukla. 2005. Use of PCR targeting of internal transcribed spacer regions and single-stranded conformation polymorphism analysis of sequence variation in different regions of rRNA genes in fungi for rapid diagnosis of mycotic keratitis. J. Clin. Microbiol. 43:662-668.

21. Larone, D. H. 2002. Medically important fungi. A guide to identification, 4th ed. ASM Press, Washington, DC.

22. Lass-Florl, C., J. Aigner, E. Gunsilius, A. Petzer, D. Nachbaur, G. Gastl, H. Einsele, J. Loffler, M. P. Dierich, and R. Wurzner. 2001. Screening for Aspergillus spp. using polymerase chain reaction of whole blood samples from patients with haematological malignancies. Br. J. Haematol. 113:180184.

23. Leaw, S. N., H. C. Chang, H. F. Sun, R. Barton, J. P. Bouchara, and T. C Chang. 2006. Identification of medically important yeast species by sequence analysis of the internal transcribed spacer regions. J. Clin. Microbiol. 44: 693-699.

24. Leinberger, D. M., U. Schumacher, I. B. Autenrieth, and T. T. Bachmann. 2005. Development of a DNA microarray for detection and identification of fungal pathogens involved in invasive mycoses. J. Clin. Microbiol. 43:49434953.

25. Lindsley, M. D., S. F. Hurst, N. J. Iqbal, and C. J. Morrison. 2001. Rapid identification of dimorphic and yeast-like fungal pathogens using specific DNA probes. J. Clin. Microbiol. 39:3505-3511.

26. Luo, G., and T. G. Mitchell. 2002. Rapid identification of pathogenic fungi directly from cultures by using multiplex PCR. J. Clin. Microbiol. 40:28602865.

27. O'Donnell, K. L., E. Cigelnik, and H. L. Nirenberg. 1998. Molecular systematics and phylogeography of the Gibberella fujikuroi species complex. Mycologia 90:465-493.

28. Pfaller, M. A., and D. J. Diekema. 2004. Rare and emerging opportunistic fungal pathogens: concern for resistance beyond Candida albicans and Aspergillus fumigatus. J. Clin. Microbiol. 42:4419-4431.

29. Playford, E. G., F. Kong, Y. Sun, H. Wang, C. Halliday, and T. C. Sorrell. 2006. Simultaneous detection and identification of Candida, Aspergillus, and Cryptococcus species by reverse line blot hybridization. J. Clin. Microbiol. 44:876-880.

30. Porteous, N., A. Grooters, S. Redding, E. Thompson, M. Rinaldi, G. De Hoog, and D. Sutton. 2003. Identification of Exophiala mesophila isolated from treated dental unit waterlines. J. Clin. Microbiol. 41:3885-3889.

31. Pryce, T. M., S. Palladino, I. D. Kay, and G. W. Coombs. 2003. Rapid identification of fungi by sequencing the ITS1 and ITS2 regions using an automated capillary electrophoresis system. Med. Mycol. 41:369-381.

32. Reiss, E., T. Obayashi, K. Orle, M. Yoshida, and R. M. Zancope-Oliveira. 2000. Non-culture based diagnostic tests for mycotic infections. Med. Mycol. 38:147-159.

33. Ribes, J. A., C. L. Vanover-Sams, and D. J. Baker. 2000. Zygomycetes in human disease. Clin. Microbiol. Rev. 13:236-301.

34. Sandhu, G. S., B. C. Kline, L. Stockman, and G. D. Roberts. 1995. Molecular probes for diagnosis of fungal infections. J. Clin. Microbiol. 33:2913-2919.

35. Selvarangan, R., U. Bui, A. P. Limaye, and B. T. Cookson. 2003. Rapid identification of commonly encountered Candida species directly from blood culture bottles. J. Clin. Microbiol. 41:5660-5664.

36. Sugita, T., A. Nishikawa, R. Ikeda, and T. Shinoda. 1999. Identification of medically relevant Trichosporon species based on sequences of the internal transcribed spacer regions and construction of a database for Trichosporon identification. J. Clin. Microbiol. 37:1985-1993.

37. Van Burik, J.-A., D. Myerson, R. W. Schreckhise, and R. A. Bowden. 1998. Panfungal PCR assay for detection of fungal infection in human blood specimens. J. Clin. Microbiol. 36:1169-1175.

38. White, P. L., A. Shetty, and R. A. Barnes. 2003. Detection of seven Candida species using the Light-Cycler system. J. Med. Microbiol. 52:229-238.

39. White, P. L., D. W. Williams, T. Kuriyama, S. A. Samad, M. A. Lewis, and R. A. Barnes. 2004. Detection of Candida in concentrated oral rinse cultures by real-time PCR. J. Clin. Microbiol. 42:2101-2107.

40. White, T. J., T. D. Burns, S. B. Lee, et al. 1990. Amplification and direct sequencing of fungal ribosomal RNA genes for phylogenetics, p. 315-322. In M. A. Innis, D. H. Gelfand, J. J. Sninsky, and T. J. White (ed.), PCR protocols. A guide to methods and applications. Academic Press Inc., San Diego, CA.

41. Wickham, C. L., M. Boyce, M. V. Joyner, P. Sarsfield, B. S. Wilkins, D. B. Jones, and S. Ellard. 2000. Amplification of PCR products in excess of 600 base pairs using DNA extracted from decalcified, paraffin wax embedded bone marrow trephine biopsies. Mol. Pathol. 53:19-23.

42. Willinger, B., A. Obradovic, B. Selitsch, J. Beck-Mannagetta, W. Buzina, H. Braun, P. Apfalter, A. M. Hirschl, A. Makristathis, and M. Rotter. 2003. Detection and identification of fungi from fungus balls of the maxillary sinus by molecular techniques. J. Clin. Microbiol. 41:581-585.

43. Yeo, S. F., and B. Wong. 2002. Current status of non-culture methods for diagnosis of invasive fungal infections. Clin. Microbiol. Rev. 15:465-484. 